\title{
A Model for Predicting Onset of Stagonospora nodorum Blotch in Winter Wheat Based on Preplanting and Weather Factors
}

\author{
L. K. Mehra, C. Cowger, and P. S. Ojiambo
}

First and third authors: Center for Integrated Fungal Research, and second author: United States Department of Agriculture-Agricultural Research Service, Department of Entomology and Plant Pathology, North Carolina State University, Raleigh 27695. Accepted for publication 2 February 2017.

\begin{abstract}
Stagonospora nodorum blotch (SNB) caused by Parastagonospora nodorum is a serious disease of wheat worldwide. In the United States, the disease is prevalent on winter wheat in many eastern states, and its management relies mainly on fungicide application after flag leaf emergence. Although SNB can occur prior to flag leaf emergence, the relationship between the time of disease onset and yield has not been determined. Such a relationship is useful in identifying a threshold to facilitate prediction of disease onset in the field. Disease occurred in 390 of 435 disease cases that were recorded across 11 counties in North Carolina from 2012 to 2014 . Using cases with disease occurrence, the effect of disease onset on yield was analyzed to identify a disease onset threshold that related time of disease onset to yield. Regression analysis showed that disease onset explained $32 \%$ of the variation in yield $(P<$ 0.0001 ) and from this relationship, day of year (DOY) 102 was identified as the disease onset threshold. Below-average yield occurred in $87 \%$ of

Subsequently, binary logistic regression models were developed to predict the occurrence and onset of SNB using preplanting factors and cumulative daily infection values ( $c D I V)$ starting 1 to 3 weeks prior to DOY 102. Logistic regression showed that previous crop, latitude, and $c D I V$ accumulated 2 weeks prior to DOY $102(c D I V .2)$ were significant $(P<0.0001)$ predictors of disease occurrence, and wheat residue, latitude, longitude, and $c D I V .2$ were significant $(P<0.0001)$ predictors of disease onset. The disease onset model had a correct classification rate of 0.94 and specificity and sensitivity rates $>0.90$. Performance of the disease onset model based on the area under the receiver operating characteristic curve (AUC), $\kappa$, and the true skill statistic (TSS) was excellent, with prediction accuracy values $>0.88$. Similarly, internal validation of the disease onset model based on AUC, $\kappa$, and TSS indicated good performance, with accuracy values $>0.88$. This disease onset prediction model could serve as a useful decision support tool to guide fungicide applications to manage SNB in wheat.
\end{abstract} the disease cases when disease onset occurred before DOY 102 but in only $28 \%$ of those cases when onset occurred on or after DOY 102.
Additional keywords: model accuracy.
Stagonospora nodorum blotch (SNB) of wheat (Triticum aestivum), caused by the fungal pathogen Parastagonospora nodorum, is an important disease in many wheat production areas around the world (Shi et al. 2016; Solomon et al. 2006). The disease is more prevalent and severe in areas with warm $\left(20\right.$ to $\left.27^{\circ} \mathrm{C}\right)$ and humid weather and frequent rainfall, as is the case in the southeastern United States, parts of Europe and Australia, and southern Brazil (Eyal et al. 1987; Solomon et al. 2006). Sources of primary inoculum in the field include infected wheat residue, ascospores from neighboring fields, and infected seed (Holmes and Colhoun 1975). Secondary infections during the growing season are driven primarily by rain-splashed conidia. The disease affects both the quantity and quality of wheat yield (Eyal 1999), and losses up to 50\% have been reported (Bhathal et al. 2003; King et al. 1983). Reduction in quality is mainly due to shriveling and discoloration of grain that results in low flour yield (McKendry et al. 1995). Losses are most significant when SNB epidemics occur from stem elongation to flag leaf emergence (Ruske et al. 2003). In addition, disease progress during the season and its potential impact on yield is influenced primarily by temperature, relative humidity $(\mathrm{RH})$, and rainfall (Mehra et al. 2015). Although the extent of yield loss depends on the timing of SNB initiation and subsequent progress during the growing season, this process has not been examined quantitatively.

SNB can be managed using fungicides and a variety of preplanting factors such as crop rotation, cultivar resistance, planting fungicide-treated seed, and tillage type (Krupinsky et al. 2007).

Corresponding author: P. S. Ojiambo; E-mail address: peter_ojiambo@ncsu.edu

(C) 2017 The American Phytopathological Society
Several studies have reported an association between these preplanting factors and SNB intensity at the end of the season (Eyal 1999; Mehra et al. 2015; Milus and Chalkley 1997; Solomon et al. 2006; Weisz 2013). Tillage type, previous crop, and amount of wheat debris in the field influence the inoculum available for infection. Wheat residue infected with $P$. nodorum can serve as a source of primary inoculum (Holmes and Colhoun 1975), especially with conservation tillage practices that result in wheat debris on the soil surface. Although wheat cultivars with moderate resistance to SNB are available, there are no cultivars with complete resistance to $P$. nodorum. Thus, disease management relies heavily on prophylactic fungicide sprays (Stover et al. 1996). Although wheat prices in the United States have increased and remained steady during the past decade (Anonymous 2015b), growers are still keen to minimize unprofitable fungicide applications. It has also been observed that fungicide application on the basis of wheat growth stage, without regard to the presence of disease, is unprofitable (Weisz et al. 2011). Thus, there is a need to increase fungicide efficiency for profitable wheat production. An indication of the risk of SNB prior to the first spray would be useful in guiding spray decisions to improve fungicide efficiency. One approach to determine the risk of SNB is to develop a model that can predict SNB onset in wheat. Information from such a model on the likelihood of early or late disease onset could be used to guide decisions on fungicide applications to avert a potential yield penalty due to SNB and to avoid unnecessary sprays. A similar framework to improve decisions on fungicide sprays has been developed for Septoria tritici blotch of wheat in the United Kingdom (te Beest et al. 2009).

Because SNB is influenced by preplanting factors and weather during the growing season, it is logical that disease onset can be 
predicted by determining the interaction between these sets of variables. Although most of the above preplanting factors have been associated with the end-of-season severity of SNB, their effect on disease occurrence (DSO) and the time of disease onset (TDO) have not been determined. Previous studies relating weather variables to the development of SNB have focused on weather during stem elongation (Cook 1977; Djurle et al. 1996; Hansen et al. 1994; Tyldesley and Thompson 1980). In general, these studies found rainfall to be a significant predictor of SNB. However, none of the studies examined how weather variables in combination with preplanting factors influence the onset or development of SNB. Temperature is an important factor in the infection process of $P$. nodorum and affects the latent period (LP) of P. nodorum (Zearfoss et al. 2011) which, in turn, influences disease onset. Infection is favored by temperatures between 15 and $25^{\circ} \mathrm{C}$ during periods of wet weather, although conidia and ascospores can germinate and cause infection between 5 and $37^{\circ} \mathrm{C}$ (King et al. 1983).

Prediction of TDO also confers other advantages in disease management for the SNB pathosystem. Early application of fungicides based on disease onset increases fungicide efficiency because a lower fungicide dose may be sufficient to keep the pathogen population low, and a lower dose can subsequently reduce selection pressure on the pathogen (van den Bosch et al. 2011). Furthermore, the time of SNB onset will affect the extent and magnitude of epidemic development during the season, given the polycyclic nature of the disease. In our previous work, we observed that early onset of SNB led to higher disease severity at the end of the season, and significant effects of disease on yield occurred only when SNB onset was early in the season (Mehra et al. 2015). Accurate prediction of disease onset also has the benefit of reducing efforts needed for SNB scouting in the field to determine if and when the first spray is required to reduce any potential yield losses.

Given the above considerations, we hypothesized that SNB onset depends on type of tillage, level of cultivar resistance to P. nodorum, seeding rate and stand density, fungicide seed treatment, location of a field, and prevailing weather. The objectives of this study were to (i) quantify the relationship between time of SNB onset and yield to identify a threshold for disease onset in winter wheat and (ii) develop a model to predict the onset of SNB based on preplanting factors and prevailing weather conditions.

\section{MATERIALS AND METHODS}

Field sites and preplanting factors. Experiments were conducted in 11 counties across three geographical regions in North Carolina (Fig. 1) during the 2011-12, 2012-13, and 2013-14 (hereafter referred to as 2012, 2013, and 2014, respectively) growing seasons (Table 1). Sites were chosen to represent diverse agronomic practices, weather conditions, and SNB epidemic histories across the state. At each site, planting was done in either a conventionally prepared or a no-tilled field, or both (Table 1). The size of experimental plots across the study were 1.0 to $1.5 \mathrm{~m}$ in width and 6.0 to $8.5 \mathrm{~m}$ in length. Production practices followed recommended guidelines (Weisz 2013), with planting dates ranging from the last week in September (in the west) to the first week in November (in the eastern Tidewater zone).

In the 2012 growing season, five soft red winter wheat cultivars with resistance ratings (RR) of 3 to 6 on a scale of 1 (most resistant) to 9 (most susceptible) were used: 'Branson' $(\mathrm{RR}=3)$, 'Dyna-Gro Dominion' (RR = 3), 'Dyna-Gro Shirley' $(\mathrm{RR}=4)$, 'SS8700' $(\mathrm{RR}=$ $3)$, and 'SY9978' $(R R=6)$. RR were determined from records of cultivar performance in the Eastern United States Septoria Nursery maintained by the United States Department of AgricultureAgricultural Research Service (USDA-ARS) (Anonymous 2011) at Raleigh and Kinston, NC. Cultivars were planted in a randomized complete block design with six replicates (blocks). These cultivars are grown commercially in the state and have similar heading dates and resistance to most of the other prevalent wheat pathogens. In the 2013 and 2014 growing seasons, two additional preplanting factors, seed treatment and seeding rate, were added at all sites. Here, treatments were laid out in a split-split-plot design with six replicates, with seed treatment as the main plot factor, seeding rate as the subplot factor, and cultivar as the sub-subplot. There were two levels of the seed treatment factor: seed treated or untreated with carboxin + thiram (Vitavax; Chemtura, Adelaide, SA, Australia). Furthermore, two levels of seeding rate, standard rate versus a reduced rate (i.e., $80 \%$ of standard rate), were examined. Four cultivars with resistance levels ranging from 4 to 7 were planted in 2013: 'Dyna-Gro 9012' (RR = 7), Dyna-Gro Shirley and 'P26R20' $(R R=4)$, and 'SS8641' $(R R=6)$. These four cultivars were also planted in 2014, except SS8641, which was replaced by 'USG3438' $(\mathrm{RR}=6)$.

Preplanting factors such as location (longitude and latitude), previous crop, and amount of wheat residue on the ground were recorded at each site. Latitude and longitude data were determined by locating the field position on Google Maps (Google Inc., Mountain View, CA). The amount (percentage) of residue on the ground was determined using the line-transect method, as described by Wollenhaupt and Pingry (1991). A tape (100 feet long, with 1 -foot interval markings) was stretched across each treatment block at a $45^{\circ}$ diagonal and the number of times that a piece of residue intersected the tape at the interval markings corresponded to the amount of residue in the plot. Preplanting factors were summarized on either an ordinal, binary, or continuous scale for subsequent data analysis (Table 1). The amount of residue was categorized as either low or high based on a previously established threshold of $20 \%$ (Mehra et al. 2015). In this study, a unique combination of preplanting factors constituted a single disease case. In total, 435 disease cases were recorded from all field experiments conducted across the entire study.

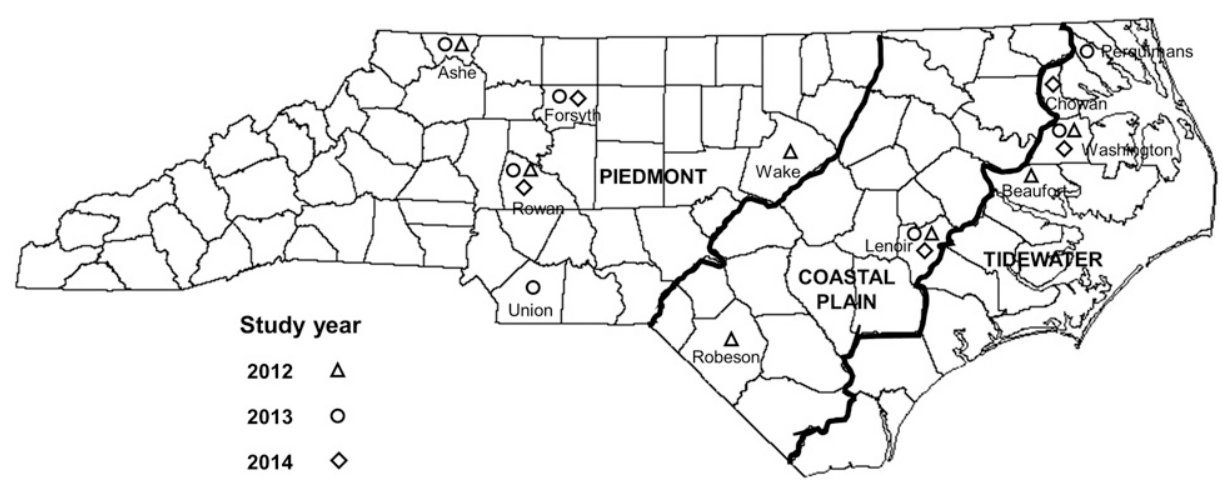

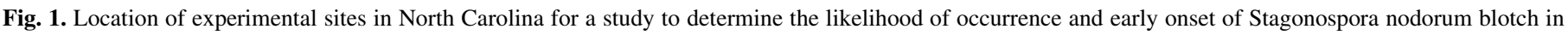

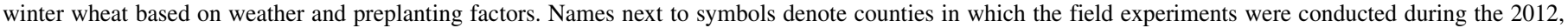
2013, and 2014 cropping seasons. 
Weather variables. Temperature, $\mathrm{RH}$, and precipitation at sites located on research stations were obtained at sensors from existing weather stations. Sensors recorded data at 1-min intervals, with temperature and $\mathrm{RH}$ being averaged and precipitation being summed over 30 -min intervals. Weather stations were located within $3 \mathrm{~km}$ of experiment fields, except for Caswell Research Farm, where the weather station was approximately $8 \mathrm{~km}$ from the field sites. Weather data for experiments on growers' fields were obtained from portable data loggers (Watchdog model 450; Spectrum Technologies, Plainfield, IL) installed in the fields. These portable loggers were programmed to record data at 30-min intervals. Daily mean temperature, daily mean $\mathrm{RH}$, and daily total rainfall were calculated from the recorded raw weather data. Rain was recorded using a tipping-bucket rain collector placed $2 \mathrm{~m}$ above the ground and connected to the data logger installed at the same height. At Tyner in 2014, the tipping-bucket malfunctioned and precipitation data were taken from the nearest State Climate Office of the North Carolina weather station.

Disease assessment and definition of disease onset. Disease incidence and severity were assessed in each experimental plot, except in 2012, when only severity was recorded. To assess disease incidence, 10 pairs of wheat tillers were arbitrarily selected in each plot and tagged in the first 2 weeks of March before any SNB symptoms were observed. Disease assessments were made starting 25 March until 30 May, except at Laurel Springs in 2013, where the final assessment was on 11 June. A tagged pair of tillers was considered diseased if it had at least one SNB lesion. Disease incidence was calculated by dividing the number of diseased tiller pairs by the total number of tagged tiller pairs and multiplying the quotient by 100 . Mean disease incidence from six replicates was then calculated for each disease case. Disease onset was defined to have occurred when the mean disease incidence for a disease case was $50 \%$.

Disease severity was assessed visually in each plot on a wholecanopy basis and was expressed as the percentage of SNBsymptomatic leaf area. Briefly, disease severity in each plot was assessed in five sections randomly selected and widely spread out within the plot, with each section measuring approximately $0.1 \mathrm{~m}^{2}$ in size. Leaf area (percent) with SNB symptoms in each section was estimated visually, and the mean symptomatic leaf area across the five sections was recorded as the overall disease severity for the plot. The lowest leaves that senesced due to maturity or abiotic factors were not included in the disease severity assessment. Two to four disease assessments were made for each of 27 of the 32 location-year combinations, whereas only one disease assessment was made for each of the remaining 5 location-year combinations due to either a shorter growing season or low levels of SNB.
A relationship between disease incidence and disease severity was determined based on data collected in 2013 and 2014. Disease incidence of $50 \%$ corresponded to $4 \%$ disease severity on a wholecanopy basis (data not shown). Thus, in 2012, where incidence was not recorded, disease onset was assumed to have occurred when the mean disease severity for a disease case was approximately $4 \%$. This threshold is similar to the $5 \%$ disease severity threshold that has been used to indicate onset of Septoria tritici blotch in wheat (Pietravalle et al. 2003). In most cases, disease incidence on a given assessment date was not exactly $50 \%$, and disease onset was estimated based on a linear rate of increase between two consecutive assessment dates. Disease cases where onset was not observed were omitted in subsequent data analyses.

Disease occurrence and establishing disease onset threshold. In the first step of the analysis, a binary variable, DSO, was defined for all disease cases as follows: DSO $=1$ if disease occurred and $\mathrm{DSO}=0$ if disease did not occur. In the second step of the analysis, the relationship between disease onset and grain yield was examined to determine a threshold for disease onset for cases where $\mathrm{DSO}=1$. Grain from each plot was harvested using a research combine and yield was calculated after adjusting grain weight to a $13.5 \%$ moisture level. The relationship between TDO and yield was determined by linear regression using PROC REG in SAS (version 9.4; SAS Institute, Cary, NC). Disease onset threshold was determined by the date (day of year [DOY]), where the 10 -year yield average of $4.03 \mathrm{tha}^{-1}$ for North Carolina (Anonymous 2015a) intersected the regression line for the relationship between disease onset and yield. Based on this threshold, a binary response variable for TDO was defined for each disease case in the second step of the analysis. If disease onset occurred before the threshold, TDO was classified as 1 (early onset), but if onset occurred on or after the threshold, TDO was classified as 0 (late onset).

Model conception. The SNB onset model is based on preplanting factors and daily infection values $(D I V)$ derived from prevailing weather conditions. Computation of DIV derives from initial work of Shane and Teng (1985) that was further refined by Wolf and Verreet (2005) to model epidemics initiated by airborne primary inoculum. $D I V$ were computed as:

$$
D I V_{i}=T_{i} \times M_{i} \in[0 ; 2]
$$

where $D I V_{i}$ is the infection value and $T_{i}$ and $M_{i}$ are the temperature and moisture indices, respectively, for day $i$. A $D I V_{i}$ of 0 implies no fungal growth, while $D I V_{i}$ of about 1 indicates optimal fungal growth.

The temperature index $T_{i}$ was expressed as the ratio between the length of the $\mathrm{LP}$ at optimum growth temperature of $22.5^{\circ} \mathrm{C}\left(L P_{o p t}\right)$ and the LP at observed daily mean temperature, $t\left(L P_{t}\right)$. Infection

TABLE 1. Experimental sites and tillage methods used in North Carolina to identify factors that influence the occurrence and onset of Stagonospora nodorum blotch in winter wheat

\begin{tabular}{|c|c|c|c|c|c|c|}
\hline \multirow[b]{2}{*}{ Site } & \multirow[b]{2}{*}{ County } & \multirow[b]{2}{*}{ Region } & \multirow[b]{2}{*}{ Field type $^{\mathrm{b}}$} & \multicolumn{3}{|c|}{ Tillage method ${ }^{a}$} \\
\hline & & & & 2012 & 2013 & 2014 \\
\hline Aurora & Beaufort & Tidewater & Grower & CT & - & - \\
\hline Caswell Farm & Lenoir & Coastal Plain & Research & - & CT, NT & - \\
\hline Hertford & Perquimans & Tidewater & Grower & - & $\mathrm{CT}, \mathrm{NT}$ & - \\
\hline Lake Wheeler Road & Wake & Coastal Plain & Research & $\mathrm{CT}$ & $\mathrm{CT}$ & - \\
\hline Monroe & Union & Piedmont & Grower & - & NT & - \\
\hline Rowland & Robeson & Coastal Plain & Grower & CT & - & - \\
\hline Upper Mountain Station & Ashe & Piedmont & Research & NT & CT, NT & - \\
\hline Walkertown & Forsyth & Piedmont & Grower & - & CT, NT & CT, NT \\
\hline
\end{tabular}

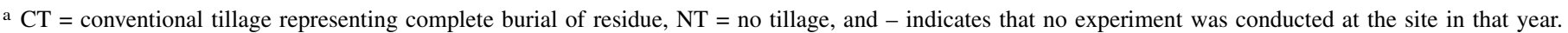

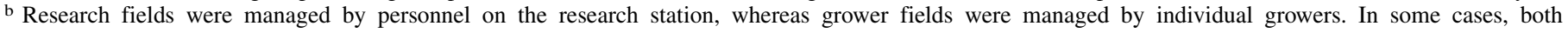
conventional- and no-tillage experiments were conducted in separate fields at the same site. 
BEST = 2 was specified to output only the best two (highest likelihood score statistic) one-predictor models, two-predictor models, and so on. The model with the lowest Bayesian information criterion (BIC) was selected as the final model. The final model selected had a BIC that was at least two units lower than the next complex model. Where two models had very similar BIC values, the model with fewer parameters was selected as the final model (Ramsey and Schafer 1997).
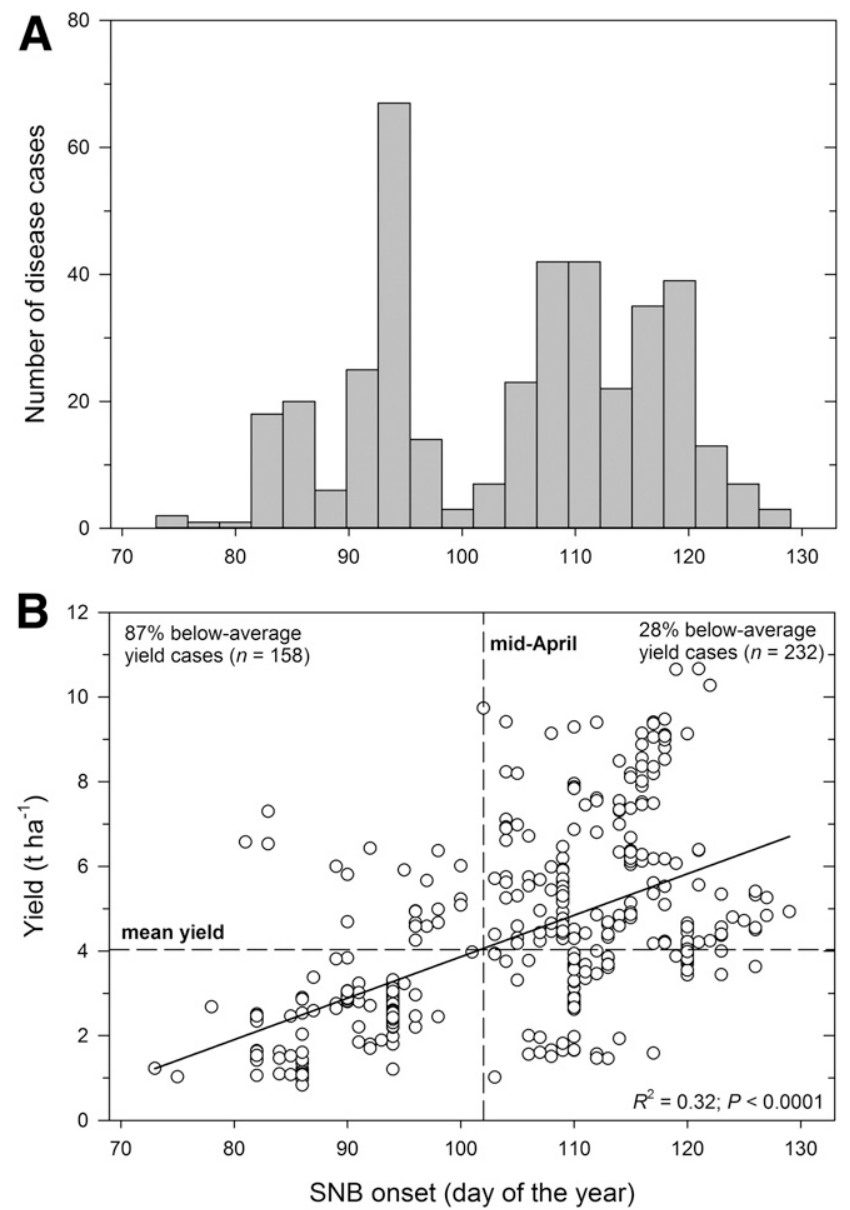

Fig. 2. A, Frequency distribution of the time of Stagonospora nodorum blotch onset in wheat for 390 disease cases (unique combinations of preplanting factors) where disease onset was observed. Disease onset occurred before midApril in 158 disease cases, whereas onset occurred on or after mid-April in 232 disease cases. B, Scatter plot showing the relationship between time of disease onset and yield. The dashed vertical line is the disease onset threshold (i.e., mid-April) whereas the dashed horizontal line represents the 10-year mean wheat yield of $4.03 \mathrm{t} \mathrm{ha}^{-1}$ in North Carolina.
The probability cutoff value, $\operatorname{Pr}(\tau)$, to classify predictions as either early- or late-onset was determined by maximizing the sum of sensitivity (i.e., proportion of correctly classified events) and specificity (i.e., proportion of correctly classified nonevents) based on the receiver operating characteristics (ROC) curve. An ROC curve is a graphical plot of sensitivity against 1-specificity and is a useful tool to evaluate model performance. If the predicted probability was $\geq \operatorname{Pr}(\tau)$, cases were classified as events, whereas, if the predicted probability was $<\operatorname{Pr}(\tau)$, cases were classified as nonevents. Differences in the distribution of observed and predicted disease cases across geographical regions was tested using PROC FREQ in SAS. Model accuracy was evaluated based on proportion of correctly classified cases, specificity, sensitivity, area under the ROC curve (AUC), and the $\kappa$ statistic (Monserud and Leemans 1992). Due to the inherent dependence of $\kappa$ on prevalence (i.e., frequency of observed events), model accuracy was also evaluated using the true skill statistic (Allouche et al. 2006). For a 2-by-2 confusion matrix, the true skill statistic (TSS) is calculated as:

$$
\begin{aligned}
\mathrm{TSS} & =(a d-b c) /[(a+c)(b+d)] \\
& =\text { Sensitivity }+ \text { Specificity }-1
\end{aligned}
$$

where $a$ and $d$ are true positive and true negative cases, respectively, while $b$ and $c$ are false positive and false negative cases, respectively. Prevalence is subsequently calculated as $(a+c) / N$, where $N=a+b+c+d$. Like $\kappa$, TSS ranges from -1 to +1 , where values of $\leq 0$ indicate performance no better than random and +1 indicates perfect agreement (Allouche et al. 2006). Goodness-of-fit measures such as concordant and discordant pairs, Somers' $D, \gamma$, and Kendall's $\tau$ - $a$ were also reported.

Internal validation of disease onset model. The BLR model used to predict TDO was internally validated using the 10fold and leave-one-out cross-validation techniques. To implement the 10 -fold cross-validation, the complete dataset $(D)$ was randomly split into $k(=10)$ mutually exclusive subsets (i.e., folds: $D_{1}, D_{2}, \ldots, D_{k}$ ) of approximately equal size. The model was trained and tested $k$ times. Each time $(\tau \in\{1,2, \ldots, k\})$, the model was trained on all but one fold $\left(D_{\tau}\right)$, and predictions were made on the single remaining fold $\left(D_{\tau}\right)$. To implement leave-one-out cross-validation, $k$ was set to equal $n$, the total number of disease cases in $D$. The model was then trained on all but one disease case and predictions were made on the single excluded case. Performance of the cross-validated models was assessed based on correct classification, specificity, sensitivity, AUC, and TSS. The ROC curves for the BLR and cross-validated models were generated to visualize model performance.

\section{RESULTS}

Disease occurrence, disease onset, and disease onset threshold. Of the 435 disease cases recorded in this study, SNB

TABLE 3. Summary of variable reduction technique and Spearman and Hoeffding coefficients for the correlation between potential predictor variables and onset of Stagonospora nodorum blotch in winter wheat

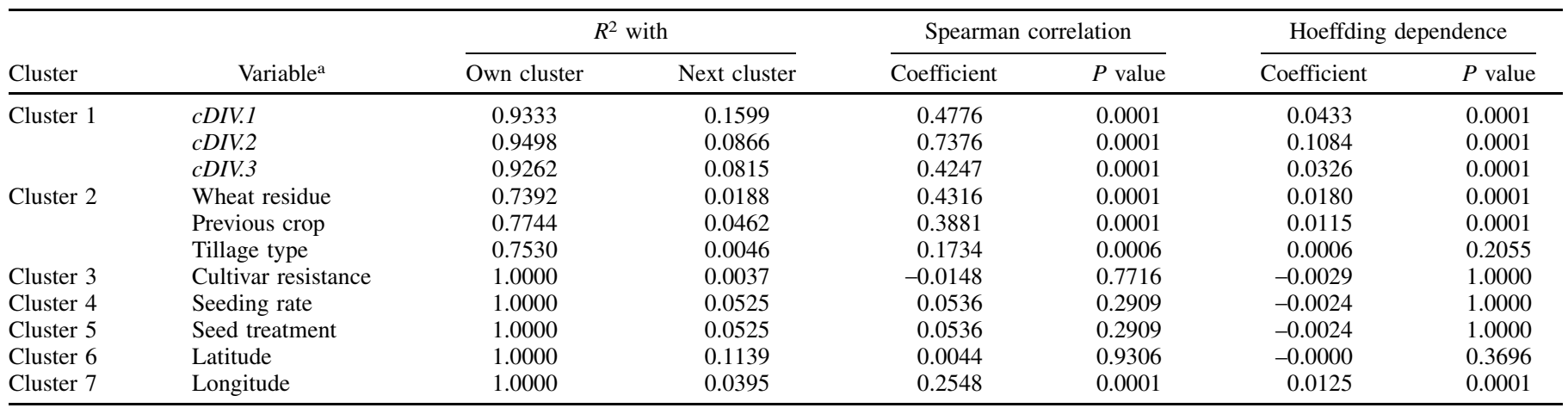

${ }^{a} c D I V=$ cumulative daily infection values summarizing favorable temperature and moisture until a given day. The variables $c D I V .1, c D I V .2$, and $c D I V .3$ are defined in Table 2. 
occurred in 390 cases, whereas no disease was observed in 45 cases. For cases where DSO was observed, TDO ranged from DOY 73 to 129 (Fig. 2A). TDO was significantly correlated with yield ( $r=$ $0.55, P<0.0001)$, and the relationship between yield and TDO was significant $\left(R^{2}=0.32, P<0.0001\right)$ based on simple linear regression (Fig. 2B). A 10-year average of wheat yield in North Carolina corresponded to a disease onset threshold of DOY 102 (i.e., midApril). Only $28 \%$ of the disease cases had lower yields than the 10 -year average if disease onset occurred on or after DOY 102, whereas
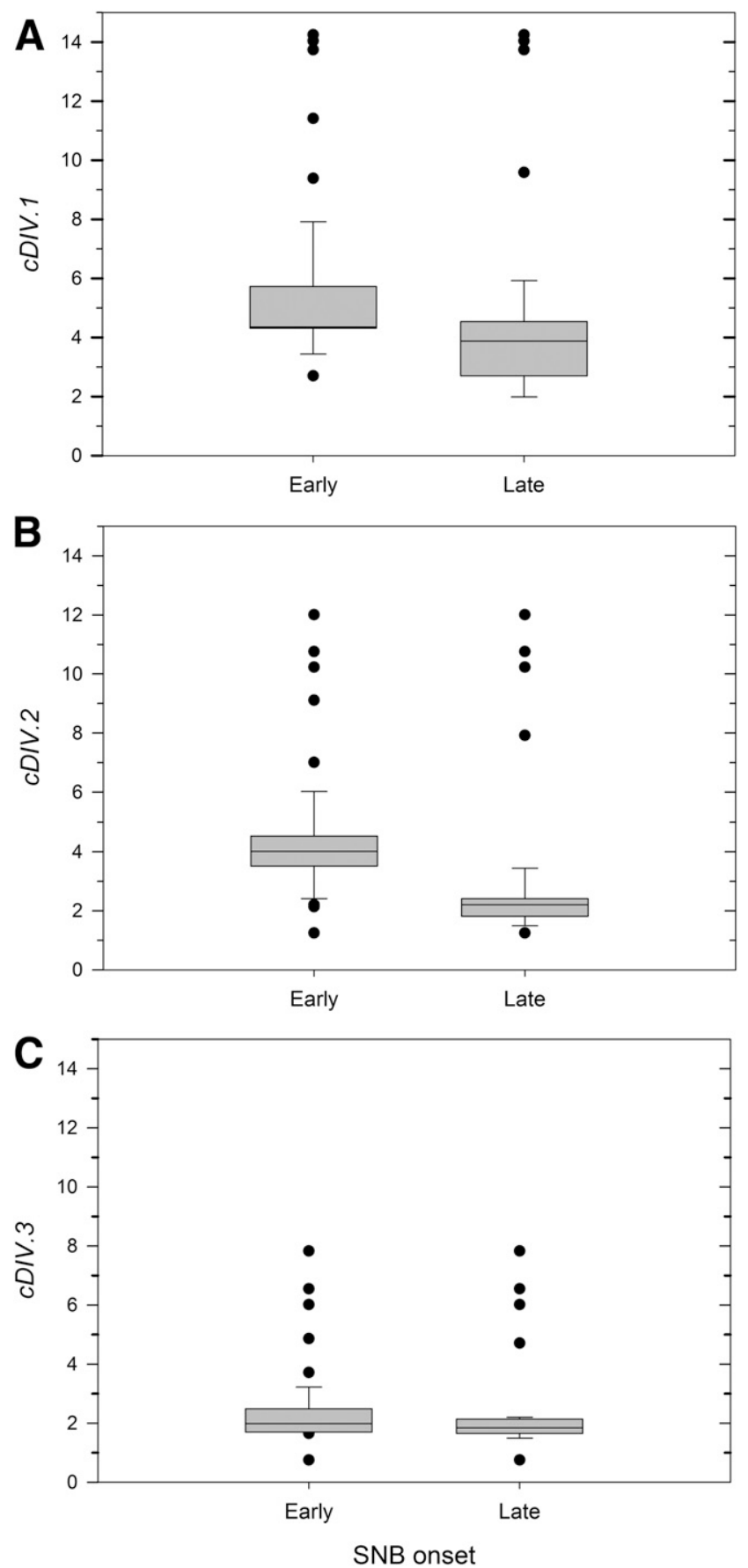

Fig. 3. Distribution of cumulative daily infection values $(c D I V)$ for early and late disease onset $\mathbf{A}, 1 ; \mathbf{B}, 2$; and $\mathbf{C}, 3$ weeks before the disease onset threshold (i.e., mid-April). Lower, middle, and upper horizontal lines of each box are 25 th, 50th (median), and 75th percentiles of the data, respectively. Vertical lines extend to 10th and 90th percentiles and solid circles are outliers. The $c D I V$ values measure the cumulative weather that is favorable for infection of wheat by Parastagonospora nodorum.
$87 \%$ of the disease cases had yields lower than the 10 -year average if disease onset occurred before DOY 102 (Fig. 2B). Disease onset before mid-April accounted for $41 \%$ of the 390 cases and disease onset on or after mid-April accounted for the remaining 59\%. The proportion of cases where SNB onset occurred before mid-April was $0.23,0.50$, and 0.56 in the Piedmont, Coastal Plain, and Tidewater regions of North Carolina, respectively (data not shown).

Selected predictor variables. The 11 predictor variables initially examined were grouped into seven clusters based on the variable reduction technique. Weather variables (i.e., $c D I V .1$ through $c D I V .3)$ were all grouped in cluster 1 , whereas wheat residue, previous crop, and tillage were grouped in cluster 2. Cultivar resistance, seeding rate, seed treatment, latitude, and longitude were all grouped singly in five separate clusters (Table 3). As expected, $c D I V .1$ and $c D I V .2$ resulted in greater separation between cases, with early and late onset of disease compared with $c D I V .3$ (Fig. 3). Generally, the range (i.e., difference between 10th and 90th percentiles) of the distribution of $c D I V$ values was higher for early- than for late-onset cases (Fig. 3).

Based on their high correlation with DSO (data not shown), $c D I V .2$ and previous crop were selected from their respective clusters. Thus, cultivar resistance, $c D I V .2$, latitude, longitude, previous crop, seeding rate, and seed treatment were selected as potential predictors for DSO in subsequent analysis. Similarly, in addition to cultivar resistance, latitude, longitude, previous crop, seeding rate, and seed treatment that clustered individually, $c D I V .2$ and wheat residue were selected from their respective clusters based on their high correlation with TDO (Table 3). These selected preplanting factors were used as potential predictors of TDO in subsequent analysis. Spearman and Hoeffding's correlation tests resulted in similar ranks for the selected predictor variables (Table 3) and none of the predictors were nonlinearly correlated with TDO.

Models and performance evaluation. Several BLR models with different combinations of predictor variables were developed to predict DSO. Six of these models were initially selected based on their BIC values (Table 4). Model BLR3 that had previous crop, latitude, and $c D I V .2$ as predictors had the lowest BIC (Table 4) and, thus, was selected to predict DSO. The percentages of concordant, discordant, and tied pairs for BLR3 were 85.1, 14.0, and 0.8\%, respectively, and Somers' $D, \gamma$, Kendall's $\tau$ - $a$, and AUC for the model were $0.71,0.72,0.13$, and 0.86 , respectively. The summation of sensitivity and specificity was greatest at probability cutoff value of 0.90 , which corresponded to a correct classification rate of 0.76 with a sensitivity and specificity of 0.73 and 0.98 , respectively.

A number of BLR models were developed to predict the probability of early onset (Table 5). These models indicated that cultivar resistance and seed treatment were not significant predictors of TDO. Models with latitude, longitude, seeding rate, wheat residue, and $c D I V .2$ as predictors were initially selected due to their BIC values. The model with wheat residue, latitude, longitude, and cDIV.2 (BLR11) had the lowest BIC value compared with the remaining candidate models with other predictor combinations (Table 5). Furthermore, the omission of longitude in BLR11 resulted in a simpler model (BLR10) with only three predictor variables but this simpler model had a higher BIC value than that of BLR11. Thus, BLR11 was selected as the final model to predict TDO based on $c D I V .2$, latitude, longitude, and wheat residue (Table 5). The percentage of concordant pairs for BLR11 was $94.7 \%$, whereas that of discordant and tied pairs was 4.9 and $0.4 \%$, respectively. Values of Somers' $D, \gamma$, and Kendall's $\tau$ - $a$ were $0.90,0.90$, and 0.43 , respectively, indicating an excellent fit of BLR11 to the data.

The sum of sensitivity and specificity was maximized with a probability cutoff of 0.42 and the final logistic regression model had a sensitivity of 0.99 and specificity of 0.91 (Table 6). The correct classification rate of the model was high, with a value of 0.94 , and the accuracy of the model as assessed by AUC, $\kappa$, and TSS was also high, with values of $0.954,0.89$, and 0.90 , respectively (Table 6). Furthermore, for a given value of $c D I V .2$, the probability of early 
disease onset was higher in fields with $>20 \%$ residue cover than in fields with $\leq 20 \%$ residue cover. Model predictions of cases with early SNB onset were similar to observed cases in all three geographical regions of North Carolina (Fig. 4). Although the model slightly overestimated cases with early disease onset in the Tidewater region, where the number of observed cases was 56 compared with 65 cases that were predicted by the model, there were no significant $\left(\chi^{2}=0.25, P=0.8813, \mathrm{df}=2\right)$ differences in the frequency of observed and predicted cases across geographical regions (Fig. 4).

Internal validation of disease onset model. The results of the 10-fold cross-validation and leave-one-out cross-validation techniques were identical and very similar to those of the final logistic regression model (Fig. 5). The AUC value for the crossvalidation models ( $\mathrm{AUC}=0.942$ to 0.946 ) was very similar to that of the final logistic model with AUC $=0.954$ (Table 6). Correct classification, sensitivity, and specificity rates for the crossvalidated models were identical to those of the final logistic model, with all the corresponding values being greater than 0.90 (Table 6). The $\kappa$ value for the cross-validation models was identical to that of the final logistic regression model, with $\kappa=0.89$. Values of TSS for the cross-validation models and final model were also identical, with TSS $=0.90$ (Table 6).

\section{DISCUSSION}

In this study, BLR models to predict the occurrence and onset of SNB in winter wheat were developed through an analysis of preplanting factors previously associated with the severity of SNB and weather during the growing season. To facilitate the analytical process, a disease onset threshold was identified from a linear regression of observed TDO and yield. Mid-April was established as a useful threshold for disease onset, and SNB onset prior to this threshold was significantly associated with a higher probability of reduced yield. Subsequently, a BLR model was used to predict SNB onset based on weather factors prior to mid-April and preplanting factors collected across diverse ecological conditions, disease histories, and cropping practices in North Carolina. Previous crop, latitude, and favorable weather for infection of wheat by $P$. nodorum until 2 weeks prior to mid-April were key predictors for the occurrence of SNB, whereas wheat residue, latitude, longitude, and favorable weather for infection of wheat by $P$. nodorum until

TABLE 4. Candidate binary logistic regression (BLR) models developed to predict the occurrence of Stagonospora nodorum blotch in winter wheat and parameter estimates for the final selected model

\begin{tabular}{|c|c|c|c|c|c|c|c|c|}
\hline Model $^{\mathrm{a}}$ & Equation $^{\mathrm{a}}$ & Estimate $^{b}$ & $\mathrm{DF}^{\mathrm{c}}$ & $\mathrm{LR} \chi^{2 \mathrm{~d}}$ & $\mathrm{SE}^{\mathrm{e}}$ & $\mathrm{BIC}^{\mathrm{f}}$ & Wald $\chi^{2}$ & $P$ value \\
\hline BLR1 & $-67.5+1.79 \mathrm{PC}+1.93 \mathrm{LAT}$ & $\ldots$ & 2 & 55.1 & $\cdots$ & 252.4 & $\ldots$ & 0.0001 \\
\hline BLR2 & $0.87+1.96 \mathrm{PC}-0.12 c D I V .2$ & $\ldots$ & 2 & 37.0 & $\ldots$ & 270.6 & $\ldots$ & 0.0001 \\
\hline BLR3 & $-96.7+1.92 \mathrm{PC}+2.72 \mathrm{LAT}+0.31 c D I V .2$ & $\ldots$ & 3 & 69.2 & $\ldots$ & 244.4 & $\ldots$ & 0.0001 \\
\hline BLR5 & $-96.5+1.94 \mathrm{PC}+2.74 \mathrm{LAT}-0.19 \mathrm{CR}+0.31 c D I V .2$ & $\ldots$ & 4 & 71.4 & $\ldots$ & 248.3 & $\ldots$ & 0.0001 \\
\hline BLR6 & $-85.4+1.94 \mathrm{PC}+2.80 \mathrm{LAT}+0.18 \mathrm{LON}+0.32 c D I V .2$ & $\ldots$ & 4 & 71.6 & $\ldots$ & 248.1 & $\ldots$ & 0.0001 \\
\hline \multicolumn{9}{|l|}{ Parameter } \\
\hline Intercept & $\ldots$ & -96.70 & 1 & $\ldots$ & 19.04 & $\ldots$ & 25.8 & 0.0001 \\
\hline$c D I V .2$ & $\ldots$ & 0.31 & 1 & $\ldots$ & 0.09 & $\ldots$ & 10.2 & 0.0014 \\
\hline
\end{tabular}

a Predictor variables are $\mathrm{PC}=$ previous crop $(1=$ wheat, $0=$ nonwheat $), c D I V .2=$ cumulative daily infection values summarizing favorable temperature and moisture until 2 weeks before day of the year 102, LAT = latitude, LON = longitude, and CR = cultivar resistance (on as scale of 1 to 9 , where $1=$ resistant and 9 = susceptible). The response variable was disease occurrence (DSO), where DSO $=1$ for cases where disease occurred and DSO $=0$ for cases where disease did not occur.

b Parameter estimates are based on BLR3, which was selected to predict disease occurrence in winter wheat.

${ }^{\mathrm{c}}$ Degrees of freedom.

d Likelihood ratio $\chi^{2}$ test against an intercept-only model and corresponding $P$ value.

e Standard error.

f Bayesian Information Criterion.

TABLE 5. Candidate binary logistic regression (BLR) models developed to predict the onset of Stagonospora nodorum blotch in winter wheat and parameter estimates for the final selected model

\begin{tabular}{|c|c|c|c|c|c|c|c|c|}
\hline Model $^{\mathrm{a}}$ & Equation $^{\mathrm{a}}$ & Estimate $^{\mathrm{b}}$ & $\mathrm{DF}^{\mathrm{c}}$ & $\mathrm{LR} \chi^{2 \mathrm{~d}}$ & $\mathrm{SE}^{\mathrm{e}}$ & $\mathrm{BIC}^{\mathrm{f}}$ & Wald $\chi^{2}$ & $P$ value \\
\hline BLR7 & $14.9+0.24 \mathrm{LON}+1.06 c$ DIV.2 & $\ldots$ & 2 & 157.7 & $\ldots$ & 386.7 & $\ldots$ & 0.0001 \\
\hline BLR8 & $-5.5+2.55 \mathrm{WR}+1.12 \mathrm{cDIV} .2$ & $\ldots$ & 2 & 229.6 & $\ldots$ & 314.9 & $\ldots$ & 0.0001 \\
\hline BLR9 & $27.6+2.94 \mathrm{WR}+0.42 \mathrm{LON}+1.03 c D I V .2$ & $\ldots$ & 3 & 252.2 & $\ldots$ & 298.2 & $\ldots$ & 0.0001 \\
\hline BLR11 & $-19.9+3.19 \mathrm{WR}+1.54 \mathrm{LAT}+0.53 \mathrm{LON}+1.15 c D I V .2$ & $\ldots$ & 4 & 263.9 & $\ldots$ & 292.4 & $\ldots$ & 0.0001 \\
\hline BLR12 & $27.5+2.97 \mathrm{WR}+0.42 \mathrm{LON}-0.42 \mathrm{SR}+1.06 c$ DIV. 2 & $\ldots$ & 4 & 254.1 & $\ldots$ & 302.2 & $\ldots$ & 0.0001 \\
\hline \multicolumn{9}{|c|}{ - } \\
\hline Intercept & $\ldots$ & -19.90 & 1 & $\ldots$ & 15.90 & $\ldots$ & 1.5 & 0.2113 \\
\hline LON & $\ldots$ & 0.53 & 1 & $\ldots$ & 0.11 & $\ldots$ & 24.5 & 0.0001 \\
\hline cDIV.2 2 & $\ldots$ & 1.15 & 1 & $\ldots$ & 0.14 & $\ldots$ & 68.1 & 0.0001 \\
\hline
\end{tabular}

a Predictor variables are $\mathrm{WR}=$ wheat residue, $c D I V .2=$ cumulative daily infection values summarizing favorable temperature and moisture until 2 weeks before day of the year $102, \mathrm{LAT}=$ latitude, $\mathrm{SR}=$ seeding rate $(1=$ standard, $0=$ reduced $)$, and $\mathrm{ST}=$ seed treatment $(1=$ yes, $0=$ no $)$. The response variable was time of disease onset (TDO), with TDO $=1$ where onset occurred before day of the year 102 and TDO $=0$ where onset occurred on or after day of the year 102 .

b Parameter estimates are based on BLR11, which was selected to predict disease onset in winter wheat prior to day of the year 102 .

c Degrees of freedom.

${ }^{\mathrm{d}}$ Likelihood ratio $\chi^{2}$ test against an intercept-only model and corresponding $P$ value.

e Standard error.

f Bayesian Information Criterion. 
2 weeks prior to mid-April were the key predictors for SNB onset. The disease onset model had a high accuracy, with internal validation indicating good performance in predicting disease onset. To the best of our knowledge, this is the first study that utilizes a combination of within-season weather and preplanting cultural factors to predict the occurrence and onset of SNB in winter wheat.

Although preplanting factors such as wheat residue coverage on the soil surface, cultivar resistance, field location, seed treatment, and seeding rate have been associated with the end of season risk of SNB in winter wheat (Mehra et al. 2015, 2016; Milus and Chalkley 1997), their importance in SNB onset has never been previously established. The model developed to predict DSO identified latitude and previous crop as the preplanting factors that were useful predictors for SNB occurrence. Previous crop is an indirect measure

TABLE 6. Performance characteristics of the final binary logistic regression model (FLR) and the 10-fold and leave-one-out cross validation models developed to predict the probability of early onset of Stagonospora nodorum blotch

\begin{tabular}{llcc}
\hline & & \multicolumn{2}{c}{ Cross-validation model } \\
\cline { 3 - 4 } Test statistic & FLR & 10-fold & Leave-one-out \\
\hline AUC $^{\mathrm{a}}$ & 0.950 & 0.946 & 0.942 \\
Correct classification $^{\mathrm{b}}$ & 0.944 & 0.944 & 0.944 \\
Sensitivity $^{\mathrm{c}}$ & 0.994 & 0.994 & 0.994 \\
Specificity $^{\mathrm{d}}$ & 0.909 & 0.909 & 0.909 \\
$\kappa^{\mathrm{e}}$ & 0.885 & 0.885 & 0.885 \\
TSS $^{\mathrm{f}}$ & 0.903 & 0.903 & 0.903 \\
\hline
\end{tabular}

a Area under the receiver operating curve (AUC) is a ranking-based measure of classification performance and provides a threshold-independent measure of the prediction accuracy of a model and values closer to 1 indicate high accuracy.

${ }^{b}$ Proportion of correctly classified cases within the dataset.

c Proportion of correctly classified cases in class $=1$ (i.e., when disease onset occurred before mid-April).

${ }^{\mathrm{d}}$ Proportion of correctly classified cases in class $=0$ (i.e., when disease onset occurred on or after mid-April).

e Statistic for an estimator of the degree of agreement between observed values and model predictions beyond random chance, with values ranging from 0 to 1 .

${ }^{\mathrm{f}}$ True skill statistic (TSS) is a synthetic index that takes into account sensitivity and specificity. TSS is not sensitive to prevalence (unlike the $\kappa$ statistics) and ranges from -1 to +1 , where values of $\leq 0$ indicate a performance no better than random and +1 indicates perfect agreement.

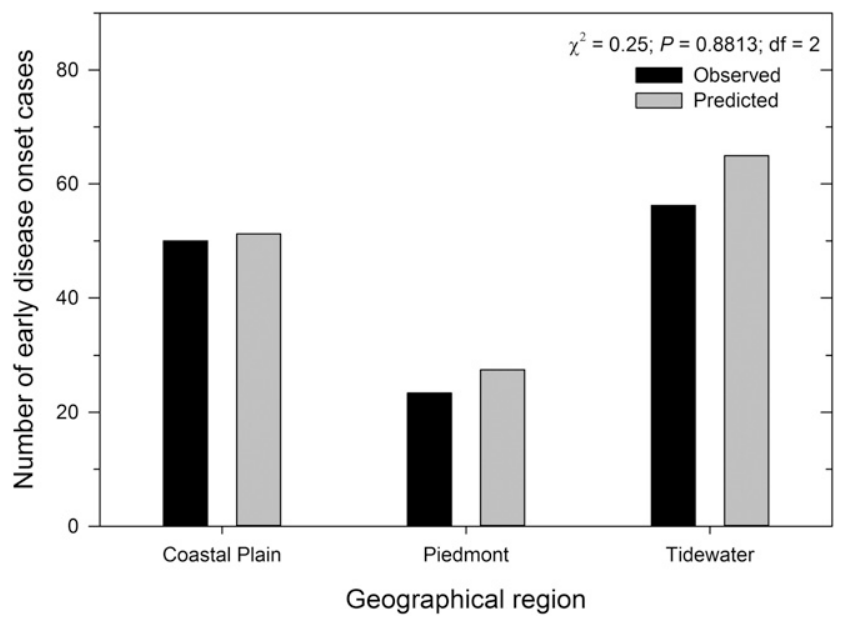

Fig. 4. Observed and predicted number of disease cases where onset of Stagonospora nodorum blotch occurred early (i.e., before mid-April) in three geographical regions of North Carolina. Predicted disease cases are from the final binary logistic regression model based on the level of wheat residue in the field, latitude, longitude, and cumulative favorable weather for infection of wheat by Parastagonospora nodorum from day of year 66 (first week of March) until 2 weeks before day of year 102 (mid-April). of pathogen inoculum, and it seems logical that the absence of host crop in previous year would reduce the probability of SNB occurrence. The importance of latitude is in agreement with observed trends in North Carolina, where SNB occurrence is more frequent in northern than in southern parts of the state (Weisz 2013). In this study, SNB occurred in $90 \%$ of the disease cases and, thus, the primary focus was to develop a model to predict TDO. The BLR model developed to predict probability of early onset identified wheat residue, latitude and longitude as the only preplanting factors that influenced the onset of SNB. Infected wheat residue is a measure of survival of the pathogen between cropping seasons and is an important indicator of the primary inoculum potential required to initiate disease. For a given accumulation of favorable weather, the probability of early SNB onset was predicted to be high in fields with $>20 \%$ wheat residue coverage. This observation is in agreement with our previous study on quantifying the effects of wheat residue on SNB severity (Mehra et al. 2015), where disease symptoms were observed earlier in residue-amended than in nonamended plots. The high predictive ability of the SNB model indicates that the wheat residue classification level used in the present study allowed for a meaningful indicator of field-specific inoculum potential that influenced disease onset in winter wheat.

Unlike wheat residue, cultivar resistance, seeding rate, and seed treatment were found to have no significant influence on disease onset. In wheat, resistance to $P$. nodorum is quantitative and partial (Solomon et al. 2006). Quantitative resistance is known to slow the rate of epidemic spread rather than delay disease onset (Vanderplank 1984). This may explain why cultivar resistance did not influence the time of SNB onset even though it is an important predictor of end-of-season SNB severity (Cowger and Murphy 2007; Weisz and Cowger 2014). The reduced seeding rate evaluated in this study may not have created a sufficiently sparser canopy to promote splash dispersal of inoculum from wheat debris to influence disease onset. In addition, a sparser canopy can result in a microclimate that is less conducive for infection by $P$. nodorum. Thus, it is also possible that

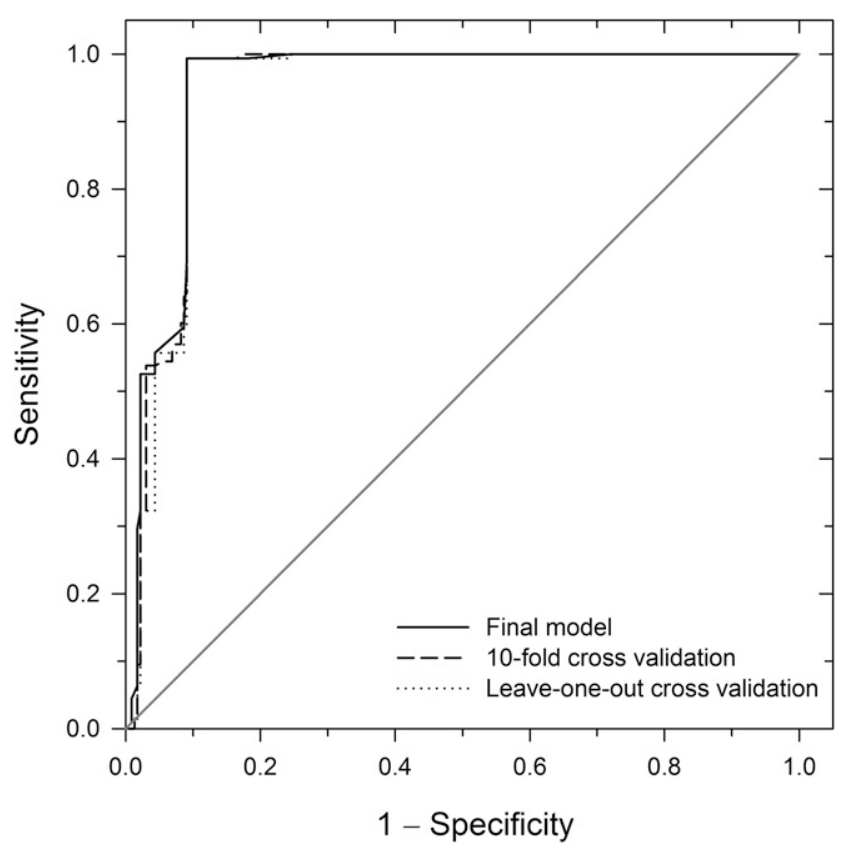

Fig. 5. Receiver operating characteristics curve for the final binary logistic regression model (BLR11) and the 10-fold and leave-one-out cross-validated models developed to predict the onset of Stagonospora nodorum blotch in winter wheat based on the amount of wheat residue in the field, latitude, longitude, and favorable weather for infection of wheat by Parastagonospora nodorum, accumulated from day of year 66 (first week of March) until 2 weeks before the disease onset threshold (i.e., mid-April). The gray line represents a hypothetical model that predicts no better than by random chance. 
the effects due to enhanced splash dispersal and less favorable microclimate off-set each other, resulting in a lack of significant effect of seeding rate on SNB onset. Seedborne inoculum has been reported to be important in initiating SNB epidemics (Shah et al. 1995), but seed treatment did not influence disease onset in the present study. This could be due to planting of certified seed in all our experiments. Furthermore, seed assays did not detect $P$. nodorum in either fungicide-treated or untreated seed.

In addition to the amount of wheat residue on the ground and field location, the prediction model for SNB onset is also based on weather-dependent $D I V$ that assumes infection will occur once temperature and moisture requirements for fungal growth are met. $D I V$ has been used to explain variation in onset times of Cercospora leaf spot in sugar beet (Wolf and Verreet 2005). Frequency analysis of accumulated DIV between emergence and disease onset has also been used to develop a model for the onset of Ascochyta blight in field pea (Schoeny et al. 2007). In the present study, DIV were accumulated 1 to 3 weeks prior to mid-April, which corresponds to stem elongation Zadoks growth stages 31 to 39 (Zadoks et al. 1974) in North Carolina. The highest degree of separation of disease cases into early- and late-onset classes was achieved by DIV accumulated 2 weeks prior to stem elongation (i.e., $c D I V .2)$. Successful implementation of the model will depend on the availability and resolution of weather variables required to calculate $D I V$. Unlike temperature and $\mathrm{RH}$, rainfall can be spatially heterogeneous over a small spatial scale (Kirchner 2006). However, the use of either $\mathrm{RH}$ or rainfall to calculate the $M_{i}$ input for the computation of $D I V$ should limit potential impacts of spatial heterogeneity of rainfall on the performance of the model in predicting time of SNB onset.

Models to predict SNB in winter wheat have previously been developed to address specific field applications. Tyldesley and Thompson (1980) developed a model to predict SNB severity based on frequency of rainfall in the United Kingdom, and they observed that more than 5 days with rainfall $>1 \mathrm{~mm}$ in the second half of May and first half of June were associated with severe SNB epidemics. Similarly, in a study conducted in Denmark, Hansen et al. (1994) observed that 8 days with rainfall $\geq 1 \mathrm{~mm}$ in a 30 -day period starting at stem elongation correlated with disease severity and yield response. However, none of these modeling approaches incorporated the effects of preplanting factors such as wheat residue and other weather variables such as temperature that are known to influence infection of wheat by P. nodorum (Djurle and Yuen 1991; Jeger et al. 1981). Moreover, SNB predictions in the study by Hansen et al. (1994) are too late to influence decisions related to fungicide application. The SNB onset model developed in the present study predicts disease onset at the start of stem elongation. This early prediction of disease onset should improve fungicide efficiency by allowing for spray applications before disease epidemics reach high levels. Given that the disease onset threshold was derived from a significant relationship between disease onset and yield, the SNB onset prediction model developed in this study should be a useful tool for making decisions on targeted scouting of SNB and the timing of the first fungicide spray. However, additional studies on the economic damage thresholds for SNB need to be conducted to determine the cost effectiveness of the timings of the first fungicide application based on model predictions.

The SNB onset model presented in this study had a high level of prediction accuracy as assessed using AUC, $\kappa$, and TSS statistics. Quantitative assessment of model performance is useful in determining the suitability of any model for specific applications and could assist in identifying aspects of the model that need to be improved (Vaughan and Ormerod 2005). The $\kappa$ statistic has been criticized for its inherent dependency on prevalence, which introduces bias and statistical artifacts in estimates of model accuracy (Allouche et al. 2006). For example, $\kappa$ is maximized by higher prevalence if sensitivity is larger than specificity but it is maximized by lower prevalence if specificity is larger than sensitivity.
However, TSS is insensitive to prevalence and was introduced to avoid bias in assessment of model accuracy (Allouche et al. 2006). In this study, although values of TSS were higher than those of $\kappa$, the two statistics were not very different. Furthermore, prevalence in the present study was $41 \%$, which is within range of the effective prevalence of $50 \%$ recommended to avoid biases in the $\kappa$ statistic (McPherson et al. 2004).

Although internal validation accuracy of the SNB onset model was high, the model needs to be externally validated prior to its implementation in other wheat-growing areas. Due to its high accuracy, the model can be expected to be widely accepted as a decision tool in the overall management program for SNB. Images of low or high residue cover on the ground can be used as references to estimate the amount of residue in the field. During each growing season, weather data 3 weeks prior to the start of the stem elongation growth stage can be downloaded from appropriate state climate agencies, depending on the field location, to calculate $c D I V .2$. An indication of the occurrence of SNB can be determined using the BLR3 model with latitude, $c D I V .2$, and previous crop as predictors and, subsequently, the risk of early disease onset can be determined using the BLR11 model based on field location, $c D I V .2$, and residue level in the field. Alternatively, a web-based application can be developed where users provide their location, information on the previous crop, and an estimate of wheat residue, and weather data can be gathered from the nearest weather station (based on their location) to calculate $c$ IIV.2. The BLR3 model can then be used to predict whether the SNB will occur and, if there is a high likelihood of occurrence, the BLR11 model can be used to predict whether onset will be early or late in that specific location. Although these models provide a simple tool to determine the probability of occurrence and onset of SNB in a given field, growers will need to monitor their fields to determine when to apply the first fungicide spray based on established thresholds. Even if these models predict a late onset or a low likelihood of SNB occurrence, it is advisable for growers to monitor their crop in the event of unexpected favorable weather conditions that could result in sudden disease outbreaks.

\section{ACKNOWLEDGMENTS}

This study was supported by Hatch Funds from North Carolina Agricultural Experiment Station Project Numbers NC02251 and NC02432, and the USDAARS. We thank all staff members at research stations and county extension offices for their assistance with the field experiments.

\section{LITERATURE CITED}

Allouche, O., Tsoar, A., and Kadmon, R. 2006. Assessing the accuracy of species distribution models: Prevalence, kappa, and the true skill statistic (TSS). J. Appl. Ecol. 43:1223-1232.

Anonymous. 2011. Eastern United States Septoria Nursery Reports 20102011. Online publication. United States Department of AgricultureAgricultural Research Service. https://www.ars.usda.gov/Main/docs.htm? docid $=8419 \&$ page $=8$

Anonymous. 2015a. Quick Stats. Online publication. United States Department of Agriculture-National Agricultural Statistics Service. https:// quickstats.nass.usda.gov/

Anonymous. 2015b. Wheat Data. Online publication. United States Department of Agriculture-Economic Research Service. https://www.ers.usda. gov/data-products/wheat-data.aspx

Bhathal, J. S., Loughman, R., and Speijers, J. 2003. Yield reduction in wheat in relation to leaf disease from yellow (tan) spot and septoria nodorum blotch. Eur. J. Plant Pathol. 109:435-443.

Cook, R. J. 1977. Effect of timed fungicide sprays on yield of winter wheat in relation to Septoria infection periods. Plant Pathol. 26:30-34.

Cowger, C., and Murphy, J. P. 2007. Artificial inoculation of wheat for selecting resistance to Stagonospora nodorum blotch. Plant Dis. 91: 539-545

Djurle, A., Ekbom, B., and Yuen, J. E. 1996. The relationship of leaf wetness duration and disease progress of glume blotch, caused by Stagonospora nodorum, in winter wheat to standard weather data. Eur. J. Plant Pathol. 102:9-20.

Djurle, A., and Yuen, J. 1991. A simulation model for Septoria nodorum in winter wheat. Agric. Syst. 37:193-218. 
Eyal, Z. 1999. The septoria tritici and stagonospora nodorum blotch diseases of wheat. Eur. J. Plant Pathol. 105:629-641.

Eyal, Z., Scharen, A. L., Prescott, J. M., and van Ginkel, M. 1987. The Septoria Diseases of Wheat: Concepts and Methods of Disease Management. CIMMYT, D.F., Mexico.

Hansen, J. G., Secher, B. J. M., Jørgensen, L. N., and Welling, B. 1994. Thresholds for control of Septoria spp. in winter wheat based on precipitation and growth stage. Plant Pathol. 43:183-189.

Holmes, S. J. I., and Colhoun, J. 1975. Straw-borne inoculum of Septoria nodorum and $S$. tritici in relation to incidence of disease on wheat plants. Plant Pathol. 24:63-66.

Jeger, M. J., Griffiths, E., and Jones, D. G. 1981. Influence of environmental conditions on spore dispersal and infection by Septoria nodorum. Ann. Appl. Biol. 99:29-34.

King, J. E., Cook, R. J., and Melville, S. C. 1983. A review of Septoria diseases of wheat and barley. Ann. Appl. Biol. 103:345-373.

Kirchner, J. W. 2006. Getting the right answers for the right reasons: Linking measurements, analyses, and models to advance the science of hydrology. Water Resour. Res. 42:W03S04.

Krupinsky, J. M., Tanaka, D. L., Merrill, S. D., Liebig, M. A., Lares, M. T., and Hanson, J. D. 2007. Crop sequence effects on leaf spot diseases of notill spring wheat. Agron. J. 99:912-920.

McKendry, A. L., Henke, G. E., and Finney, P. L. 1995. Effects of Septoria leaf blotch on soft red winter wheat milling and baking quality. Cereal Chem. 72:142-146.

McPherson, J. M., Jetz, W., and Rogers, D. J. 2004. The effects of species' range sizes on the accuracy of distribution models: Ecological phenomenon or statistical artefact? J. Appl. Ecol. 41:811-823.

Mehra, L. K., Cowger, C., Gross, K., and Ojiambo, P. S. 2016. Predicting preplanting risk of Stagonospora nodorum blotch in winter wheat using machine learning models. Front. Plant Sci. 7:390.

Mehra, L. K., Cowger, C., Weisz, R., and Ojiambo, P. S. 2015. Quantifying the effects of wheat residue on severity of Stagonospora nodorum Blotch and yield in winter wheat. Phytopathology 105:1417-1426.

Milus, E. A., and Chalkley, D. B. 1997. Effect of previous crop, seedborne inoculum, and fungicides on development of Stagonospora blotch. Plant Dis. 81:1279-1283.

Monserud, R. A., and Leemans, R. 1992. Comparing global vegetation maps with the Kappa statistic. Ecol. Modell. 62:275-293.

Nelson, B. D. 2001. Variable reduction for modeling using PROC VARCLUS. Paper No. 261-26 in: Proc. 26 Annu. SAS Users Group Int. Conf. SAS Institute Inc., Cary, NC. http://www2.sas.com/proceedings/sugi26/p261-26.pdf

Pietravalle, S., Shaw, M. W., Parker, S. R., and Van Den Bosch, F. 2003. Modeling of relationships between weather and Septoria tritici epidemics on winter wheat diseases: A critical approach. Phytopathology 93:1329-1339.

Ramsey, F. L., and Schafer, D. W. 1997. The Statistical Sleuth. Duxbury Thomson Learning, Pacific Grove, CA.

Ruske, R. E., Gooding, M. J., and Jones, S. A. 2003. The effects of adding picoxystrobin, azoxystrobin and nitrogen to a triazole programme on disease control, flag leaf senescence, yield and grain quality of winter wheat. Crop Prot. 22:975-987.
Schoeny, A., Jumel, S., Rouault, F., Le May, C., and Tivoli, B. 2007. Assessment of airborne primary inoculum availability and modelling of disease onset of ascochyta blight in field peas. Eur. J. Plant Pathol. 119:87-97.

Shah, D., Bergstrom, G. C., and Ueng, P. P. 1995. Initiation of Septoria nodorum blotch epidemics in winter wheat by seedborne Stagonospora nodorum. Phytopathology 85:452-457.

Shane, W. W., and Teng, P. S. 1985. Evaluation and implementation of the Cercospora leaf spot prediction model. Sugar Beet Res. Ext. Rep. 15:129-138.

Shi, G., Zhang, Z., Friesen, T. L., Bansal, U., Cloutier, S., Wicker, T., Rasmussen, J. B., and Faris, J. D. 2016. Marker development, saturation mapping, and high-resolution mapping of the Septoria nodorum blotch susceptibility gene Snn3-B1 in wheat. Mol. Genet. Genomics 291:107-119.

Solomon, P. S., Lowe, R. G. T., Tan, K.-C., Waters, O. D. C., and Oliver, R. P. 2006. Stagonospora nodorum: Cause of stagonospora nodorum blotch of wheat. Mol. Plant Pathol. 7:147-156.

Stover, R. W., Francl, L. J., and Jordahl, J. G. 1996. Tillage and fungicide management of foliar diseases in a spring wheat monoculture. J. Prod. Agric. 9:261-265.

te Beest, D. E., Shaw, M. W., Pietravalle, S., and Van Den Bosch, F. 2009. A predictive model for early-warning of Septoria leaf blotch on winter wheat. Eur. J. Plant Pathol. 124:413-425.

Tyldesley, J. B., and Thompson, N. 1980. Forecasting Septoria nodorum on winter wheat in England and Wales. Plant Pathol. 29:9-20.

van den Bosch, F., Paveley, N., Shaw, M., Hobbelen, P., and Oliver, R. 2011. The dose rate debate: Does the risk of fungicide resistance increase or decrease with dose? Plant Pathol. 60:597-606.

Vanderplank, J. E. 1984. Disease Resistance in Plants, 2nd ed. Academic Press, New York.

Vaughan, I. P., and Ormerod, S. J. 2005. The continuing challenges of testing species distribution models. J. Appl. Ecol. 42:720-730.

Weisz, R. 2013. Small Grain Production Guide. Publ. No. AG-580. North Carolina Cooperative Extension Service, Raleigh, NC.

Weisz, R., and Cowger, C. 2014. 2014 Wheat variety performance \& recommendations. SmartGrains - The Small Grains Fact Sheet, No. 37. Online publication. NC State University. http://www.smallgrains.ncsu.edu/_Misc/_ VarietySelection.pdf

Weisz, R., Cowger, C., Ambrose, G., and Gardner, A. 2011. Multiple midAtlantic field experiments show no economic benefit to fungicide application when fungal disease is absent in winter wheat. Phytopathology 101: 323-333.

Wolf, P. F. J., and Verreet, J. A. 2005. Factors affecting the onset of Cercospora leaf spot epidemics in sugar beet and establishment of disease-monitoring thresholds. Phytopathology 95:269-274.

Wollenhaupt, N. C., and Pingry, J. 1991. Estimating Residue using the Linetransect Method. Coop. Ext. Publ. No. A3553. University of Wisconsin, Madison.

Zadoks, J. C., Chang, T. T., and Konzak, C. F. 1974. A decimal code for the growth stages of cereals. Weed Res. 14:415-421.

Zearfoss, A. D., Cowger, C., and Ojiambo, P. S. 2011. A degree-day model for latent period of Stagonospora nodorum blotch in winter wheat. Plant Dis. 95:561-567. 